\title{
Epidemiology of Chronic Hepatitis C Infections at a Tertiary Care Centre in Oman
}

"Said A. Al-Busafi, ${ }^{1}$ Halima Al-Shuaili, ${ }^{2}$ Heba Omar, ${ }^{3}$ Haifa Al-Zuhaibi, ${ }^{1}$ L. Jeyaseelan,,${ }^{4,5}$ Khalid Al-Naamani ${ }^{3}$

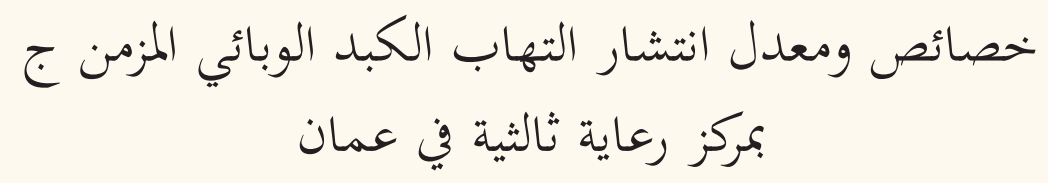

سعيد البوصافي، حليمة الشعيلية، هبة عمر، هيفا الزهيبية، جيسيلان، خالد النعماني

ABSTRACT: Objectives: Chronic hepatitis $\mathrm{C}(\mathrm{CHC})$ is a leading cause of liver cirrhosis and hepatocellular carcinoma (HCC) worldwide. However, there is a lack of data regarding the epidemiology of CHC in Oman. This study aimed to describe the clinicopathological characteristics and outcomes of $\mathrm{CHC}$-infected patients at a tertiary care hospital in Oman. Methods: This retrospective descriptive hospital-based study included all CHC-infected patients who presented to the Sultan Qaboos University Hospital (SQUH) in Muscat, Oman, between January 2010 and December 2015. The baseline demographic, clinical, laboratory and radiological data of the patients were analysed. Results: A total of $603 \mathrm{CHC}$-infected patients were identified during the study period; of these, $65.8 \%$ were male and the mean age was $44.8 \pm 16.5$ years. The main risk factors associated with $\mathrm{CHC}$ infection were intravenous drug abuse (23.9\%) and a history of blood transfusions (20.7\%). The most prevalent virus genotypes were 1 and 3 (44.0\% and 35.1\%, respectively). Upon initial presentation, 33.0\% of the cohort had liver cirrhosis; of these, $48.7 \%$ had decompensated cirrhosis and $23.1 \%$ had HCCs. Liver transplantation was only performed for $7.5 \%$ of the cirrhosis patients, mostly as a curative treatment for HCC. Conclusion: The implementation of national policies to prevent hepatitis $\mathrm{C}$ transmission and encourage the early screening of at-risk patients is recommended to reduce the burden and consequences of this disease in Oman.

Keywords: Chronic Hepatitis C; Hepatocellular Carcinoma; Liver Cirrhosis; Infectious Disease Transmission; Genotypes; Oman.

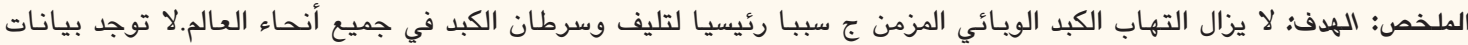

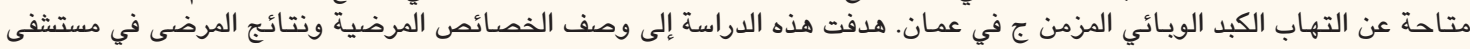

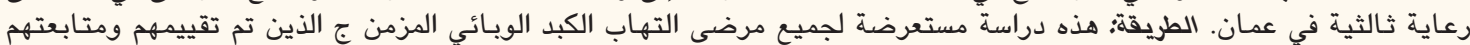

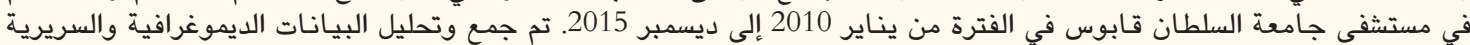

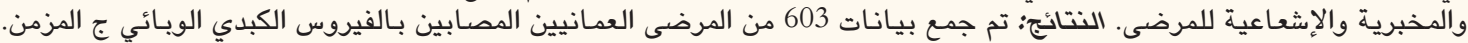

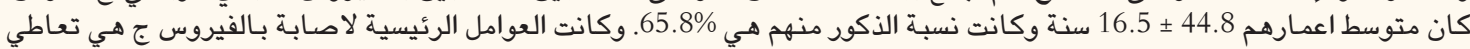

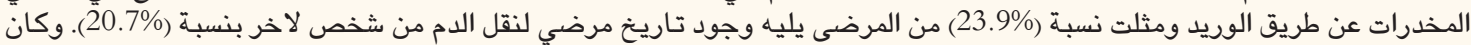

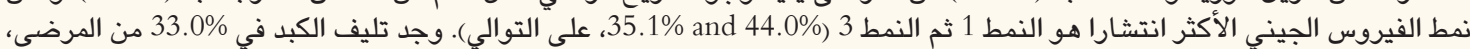

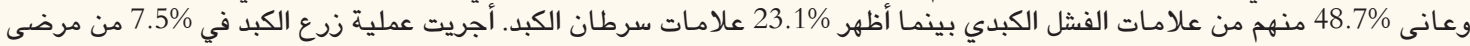

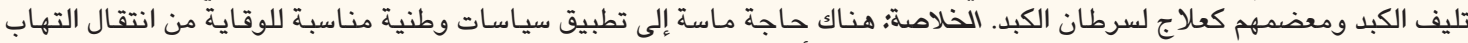

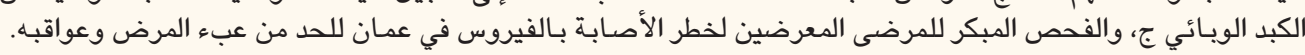

الكلمات المفتاحية: التهاب الكبد الوبائي المزمن ج؛ الأنماط الجينية؛ سرطان الكبد؛ تليف الكبد؛ إنتقال العدوى؛ عمان.

\section{AdVANCES IN KNOWLEDGE}

To the best of the authors' knowledge, the current study is the first to describe the clinical characteristics, risk factors, genotypes and outcomes of chronic hepatitis C (CHC)-infected patients in Oman.

In the current study, CHC-infected patients who were diagnosed based on existing evidence of liver disease had a higher prevalence of cirrhosis and hepatocellular carcinoma compared to patients who were diagnosed as a result of routine screening.

\section{Application to Patient Care}

The results of this study emphasise the importance of implementing national policies for preventing the transmission of the hepatitis $C$ virus in Oman. Early screening of at-risk patients and prompt management will help to reduce the burden of this disease. 
C URRENTly, THE hepatitis C Virus (hCV) infects approximately 177-185 million individuals worldwide. ${ }^{1}$ Chronic hepatitis $\mathrm{C}(\mathrm{CHC})$ infection is a gradual progressive disease characterised by persistent hepatic inflammation. It leads to the development of cirrhosis in approximately 20-30\% of patients over 15-25 years; of those with cirrhosis, $1 \%$ subsequently develop hepatocellular carcinoma (HCC) every year. ${ }^{1,2}$ With the recent development of oral direct-acting antiviral agents, the elimination of HCV within the next $15-20$ years is predicted. $^{1}$ Unfortunately, liver cirrhosis and $\mathrm{HCC}$ rates are nevertheless expected to continue rising among $\mathrm{HCV}$ infected patients as many cases remain undiagnosed and risk factors go unrecognised. ${ }^{3,4}$ Screening programmes to enhance the early detection of infected patients and improve prevention strategies have been proven to reduce $\mathrm{HCV}$-associated morbidity and mortality. ${ }^{5}$ Most patients with acute $\mathrm{HCV}$ infections remain asymptomatic; as such, progression to a chronic subclinical infection is very common. Usually, liver cirrhosis and other $\mathrm{HCV}$-related complications occur approximately 20-30 years following HCV exposure. ${ }^{6}$ In the absence of proper $\mathrm{HCV}$ screening, infected patients frequently present at a late stage with multiple complications..$^{5-7}$ The presence of comorbidities like alcoholic liver disease, viral coinfection with HIV or hepatitis $B$ and the presence of insulin resistance can further accelerate disease progression. ${ }^{8-11}$

In Oman, there are currently no national programmes in effect to promote public awareness, enhance early diagnosis or enable prompt management of CHC cases. In 1991, HCV testing was first introduced at the Sultan Qaboos University Hospital (SQUH), a tertiary referral hospital in Muscat, Oman. ${ }^{12}$ The estimated prevalence of anti-HCV-antibodies in Oman has been reported as $1 \%$ among healthy blood donors, $41 \%$ among thalassaemic patients undergoing regular blood transfusions and 26.5\% among patients on haemodialysis. ${ }^{12,13}$ However, more studies are needed to provide necessary information regarding $\mathrm{HCV}$ infection rates to policy-makers and health planners in Oman. This study therefore aimed to identify the clinical characteristics, risk factors and major clinical outcomes of $\mathrm{CHC}$-infected patients at a tertiary care centre in Oman.

\section{Methods}

This retrospective descriptive hospital-based study was conducted at SQUH and included all patients with CHC infections presenting between January 2010 and December 2015. All CHC infections were diagnosed based on positive anti-HCV antibody and HCV ribo- nucleic acid polymerase chain reaction test results. Patients were diagnosed with liver cirrhosis based on the presence of cirrhotic changes on an abdominal ultrasound scan, liver stiffness measurements of $>12.5 \mathrm{kPa}$ using a FibroScan ${ }^{\circledR}$ elastography device (Echosens $^{\mathrm{TM}}$, Paris, France) within 12 months of inclusion in the study, a fibrosis- 4 score of $>3.25$ or histopathological findings. Patients with acute $\mathrm{HCV}$ infections, incomplete records or those who were lost to follow-up were excluded from the study. The final sample was estimated to be representative of the national population. Information regarding the demographic and clinical characteristics, risk factors for HCV transmission, histological/radiological data and outcomes of the patients were subsequently collected from electronic hospital records.

Data were analysed using the Statistical Package for the Social Sciences (SPSS), Version 17.0 (IBM Corp., Armonk, New York, USA). Results were expressed as numbers and percentages for categorical variables and as means and standard deviations for continuous

Table 1: Sociodemographic characteristics of chronic hepatitis C-infected patients at the Sultan Qaboos University Hospital, Muscat, Oman ( $=603$ )

$\begin{array}{lc}\text { Variable } & \mathbf{n}(\%) \\ \text { Age in years } & \\ <50 & 370(61.4) \\ \geq 50 & 233(38.6) \\ \text { Mean } \pm \text { SD } & 44.8 \pm 16.5 \\ \text { Gender } & \\ \text { Male } & 397(65.8) \\ \text { Female } & 206(34.2) \\ \text { BMI in kg/m }{ }^{2 *} & \\ <29.8 & 416(79.5) \\ >29.9 & 107(20.5) \\ \text { Mean } \pm \text { SD } & 25.9 \pm 8.1 \\ \text { Place of residence } & \\ \text { Muscat } & \\ \text { Al-Batinah } & 311(51.6) \\ \text { Other } & 102(16.9) \\ \text { Abroad } & 190(31.5) \\ \text { Risky behaviour } & 34 .(5.6) \\ \text { Alcohol consumption } & \\ \text { Smoking } & \\ \text { SD standard deviation; BMI = body mass index. } \\ \text { excluded. }\end{array}$




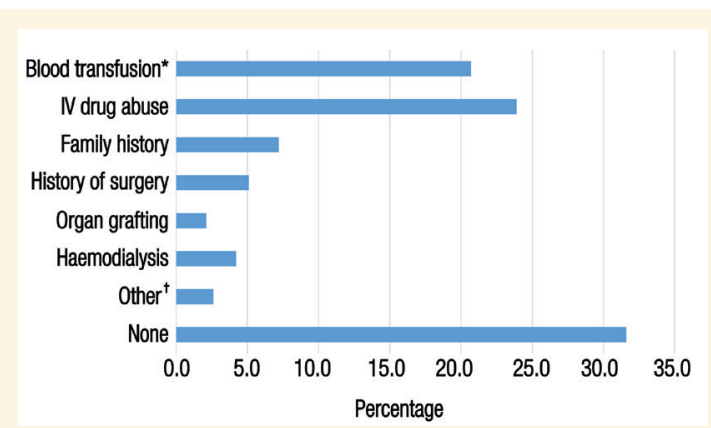

Figure 1: Risk factors for hepatitis $C$ virus infection among chronic hepatitis C-infected patients at the Sultan Qaboos University Hospital, Muscat, Oman $(\mathrm{N}=569)^{\ddagger}$

$I V=$ intravenous

"Of these transfusions, 13.0\% were performed before 1991. ${ }^{+}$Including extramarital relationships $(1.7 \%)$, sharp needle stick injuries (0.5\%) and tattooing (0.4\%). ${ }^{\ddagger}$ Total dataset for this variable was 569 as 34 patients were excluded due to missing data.

variables. The relationships between genotype distribution and age, place of residence and mode of transmission were examined using a Chi-squared test. All statistical analyses were based on two-sided hypothesis tests with a significance level set at $P<0.050$.

This study was approved by the Medical Research \& Ethics Committee of the College of Medicine \& Health Sciences, Sultan Qaboos University (MREC \#844).

\section{Results}

A total of 603 patients with confirmed $\mathrm{CHC}$ infections presented to SQUH during the study period. The mean age of the patients was $44.8 \pm 16.5$ years (range: 5-90 years old) and the majority were male (65.8\%). Excluding 80 patients with ascites, $20.5 \%$ of the sample were classified as obese with a body mass index of $>29.9 \mathrm{~kg} / \mathrm{m}^{2}$. Alcohol consumption and smoking were reported by 103 (17.1\%) and 68 (11.3\%) patients, resp- ectively [Table 1]. Out of 569 patients with available data, 392 (68.9\%) had identifiable HCV risk factors. The most commonly identified risk factors were intravenous drug abuse (23.9\%) followed by blood transfusions (20.7\%), most of which had been performed before 1991. Other risk factors included a history of surgery (5.1\%), a family history of infection (7.2\%), haemodialysis (4.2\%) and organ grafting (2.1\%) [Figure 1].

Overall, routine $\mathrm{HCV}$ testing was performed for 290 patients $(48.1 \%)$ based on standard indications, including for patients undergoing frequent blood transfusions and screening prior to invasive procedures or blood donations and as part of pre-employment conditions. Of the screened patients, 46 (15.9\%) and $11(3.8 \%)$ had liver cirrhosis and HCC, respectively. On the other hand, 258 cases (42.8\%) were diagnosed based on various liver disease-related findings (e.g. elevated liver enzymes, acute hepatitis or acute variceal bleeding). Within that subgroup, a higher proportion of patients with liver cirrhosis or HCC were identified (47.3\% and $12.4 \%$, respectively) [Figure 2].

The vast majority of patients (84.4\%) were asymptomatic at the time of initial presentation. For symptomatic patients, dyspepsia (62.8\%), fatigue (60.6\%), abdominal pain (58.5\%) and jaundice (26.6\%) were the predominant symptoms reported. A total of $55.6 \%$ of the patients had low viral loads. Most patients had at least one comorbidity, including hypertension (21.6\%), diabetes (20.7\%), anaemia (19.2\%), renal impairment (13.6\%) or cardiac conditions (13.1\%). Coinfections with chronic hepatitis B or HIV was reported in $39.0 \%$ and $2.0 \%$ of patients, respectively. [Table 2]. The most prevalent $\mathrm{HCV}$ genotype was genotype 1 (44.0\%) followed by genotypes 3 (35.1\%), 4 (15.0\%), 2 (3.7\%) and mixed (2.2\%). For intravenous drug abusers, the most common genotype was 3 (53.0\%) followed by
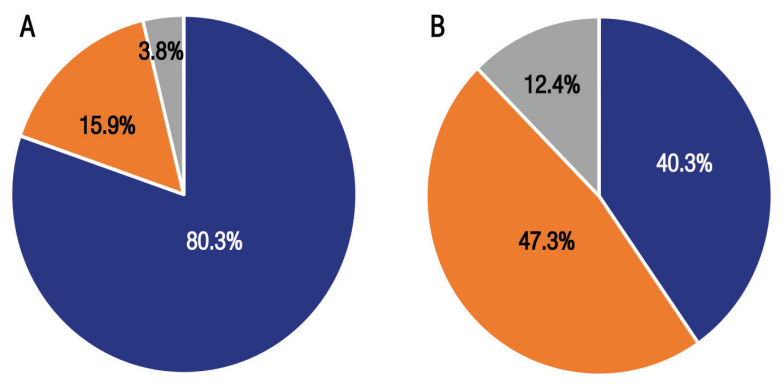

Nelther Cirnosis HCC

Figure 2: Prevalence of liver cirrhosis and hepatocellular carcinoma among chronic hepatitis C-infected patients diagnosed as a result of $(A)$ routine screening $(n=290)$ and $(B)$ as a result of existing evidence of liver disease $(\mathrm{n}=258)$ at the Sultan Qaboos University Hospital, Muscat, Oman ( $=548)^{*}$.

HCC = hepatocellular carcinoma.

"Total dataset for this variable was 548 as 55 patients were excluded due to missing data. 
Table 2: Baseline clinical characteristics among chronic hepatitis C-infected patients at the Sultan Qaboos University Hospital, Muscat, Oman ( $=603)$

\begin{tabular}{|c|c|}
\hline Characteristics & n (\%) \\
\hline \multicolumn{2}{|l|}{ Symptoms ${ }^{* \dagger}$} \\
\hline Dyspepsia & $59(62.8)$ \\
\hline Fatigue & $57(60.6)$ \\
\hline Abdominal pain & $55(58.5)$ \\
\hline Jaundice & $25(26.6)$ \\
\hline Nausea and vomiting & $21(22.3)$ \\
\hline \multicolumn{2}{|l|}{ Viral load in IU/mL } \\
\hline$<800,000$ & $335(55.6)$ \\
\hline$\geq 800,000$ & $268(44.4)$ \\
\hline \multicolumn{2}{|l|}{ Comorbidities $^{\dagger}$} \\
\hline HTN & $130(21.6)$ \\
\hline $\mathrm{DM}$ & $125(20.7)$ \\
\hline Anaemia $^{\ddagger}$ & $116(19.2)$ \\
\hline Renal impairment & $82(13.6)$ \\
\hline Cardiac conditions & $79(13.1)$ \\
\hline Dyslipidaemia & $67(11.1)$ \\
\hline Psychological disorders & $45(7.5)$ \\
\hline Autoimmune diseases & $42(7.0)$ \\
\hline Sickle cell disease & $40(6.6)$ \\
\hline Malignancies & $35(5.8)^{\S}$ \\
\hline Neutropaenia & $33(5.5)$ \\
\hline Thalassaemia major & $25(4.1)$ \\
\hline Haemophilia & $5(0.8)$ \\
\hline \multicolumn{2}{|l|}{ Coinfections } \\
\hline Hepatitis B/ & $213(39.0)$ \\
\hline HIV $^{* * *}$ & $10(2.0)$ \\
\hline
\end{tabular}

*Total dataset for this variable was 94 as 509 asymptomatic patients were excluded. +Percentages for these variables add up to more than $100 \%$ as some patients may have reported multiple symptoms/ comorbidities. ${ }^{\neq}$Defined as a haemoglobin level of $<10 \mathrm{mg} / \mathrm{dL}$. ${ }^{.} \mathrm{Of}$ these, six cases had lymphoma. 'Defined as an absolute neutrophil count of $<1,000$. "Out of 546 patients who underwent hepatitis B core antibody testing. *"Out of 494 patients who underwent HIV testing.

1 (40.9\%). Among those with a history of blood transfusions, genotype 1 was the most prevalent (59.1\%) followed by 3 (20.9\%). There were significant associations between genotype distribution and age, place of residence and mode of transmission $(P<0.050$ each) [Table 3].

A total of 199 patients (33.0\%) had liver cirrhosis upon initial presentation. Of these, 97 (48.7\%) had one or more features suggestive of hepatic decomp-
Table 3: Genotype distribution according to age, residence and mode of transmission among chronic hepatitis C-infected patients at the Sultan Qaboos University Hospital, Muscat, Oman $(\mathrm{N}=539)^{*}$

\begin{tabular}{|c|c|c|c|c|c|}
\hline \multirow[t]{2}{*}{ Variable } & \multirow[t]{2}{*}{ Total } & \multicolumn{3}{|c|}{ Genotype, n (\%) } & \multirow{2}{*}{$\begin{array}{c}P \\
\text { value }\end{array}$} \\
\hline & & 1 & 3 & Other & \\
\hline Younger age $^{+}$ & 318 & $\begin{array}{c}151 \\
(47.5)\end{array}$ & $\begin{array}{c}117 \\
(36.8)\end{array}$ & $\begin{array}{c}50 \\
(15.7)\end{array}$ & 0.002 \\
\hline \multicolumn{6}{|c|}{ Place of residence } \\
\hline Muscat & 268 & $\begin{array}{c}111 \\
(41.4)\end{array}$ & $\begin{array}{c}113 \\
(42.2)\end{array}$ & $\begin{array}{c}44 \\
(16.4)\end{array}$ & \multirow{4}{*}{$<0.001$} \\
\hline Al-Batinah & 93 & $\begin{array}{c}45 \\
(48.4)\end{array}$ & $\begin{array}{c}30 \\
(32.3)\end{array}$ & $\begin{array}{c}18 \\
(19.4)\end{array}$ & \\
\hline Other & 145 & $\begin{array}{c}75 \\
(51.7)\end{array}$ & $\begin{array}{c}40 \\
(27.6)\end{array}$ & $\begin{array}{c}30 \\
(20.7)\end{array}$ & \\
\hline Abroad & 27 & $\begin{array}{c}6 \\
(22.2)\end{array}$ & $6(22.2)$ & $\begin{array}{c}15 \\
(55.6)\end{array}$ & \\
\hline \multicolumn{6}{|c|}{ Mode of transmission } \\
\hline IV drug abuse & 115 & $\begin{array}{c}47 \\
(40.9)\end{array}$ & $\begin{array}{c}61 \\
(53.0)\end{array}$ & $7(6.1)$ & \multirow{2}{*}{$<0.001$} \\
\hline $\begin{array}{l}\text { Blood } \\
\text { transfusions }\end{array}$ & 115 & $\begin{array}{c}68 \\
(59.1)\end{array}$ & $\begin{array}{c}24 \\
(20.9)\end{array}$ & $\begin{array}{c}23 \\
(20.0)\end{array}$ & \\
\hline
\end{tabular}

$I V=$ intravenous

*Total dataset for this variable was 539 as 64 patients were excluded due to missing genotype data. ${ }^{\dagger}$ Age of $<50$ years old.

ensation, including portal hypertension, ascites, hypersplenism, hepatic encephalopathy, hepatorenal syndrome or hepatic hydrothorax. A total of 61 patients with liver cirrhosis (30.7\%) were diagnosed with HCC; among these cases, 27 (44.3\%) had advanced HCC beyond the Milan criteria for liver transplantation. ${ }^{14}$ Only 15 cirrhosis patients (7.5\%) underwent liver transplantation, for which the most common indication was as therapeutic management for early-stage HCC ( $\mathrm{n}=8 ; 53.3 \%)$ [Figure 3].

\section{Discussion}

Controlling $\mathrm{HCV}$ infections is of critical importance to prevent $\mathrm{CHC}$ progression and the subsequent development of decompensated cirrhosis and HCC. However, the asymptomatic nature of most $\mathrm{CHC}$ cases clearly limits this objective. ${ }^{15,16}$ Moreover, Oman has no community-based screening programme to target its high-risk population. To the best of the authors' knowledge, the current study is the first to report the clinical characteristics and outcomes of $\mathrm{CHC}$-infected patients in Oman. Overall, the findings indicated that most patients resided in the highly-populated Muscat and Al-Batinah governorates. Similar results have been reported in Western countries, with a greater prevalence of $\mathrm{HCV}$ in high-population compared to low-population communities, possibly due to the 


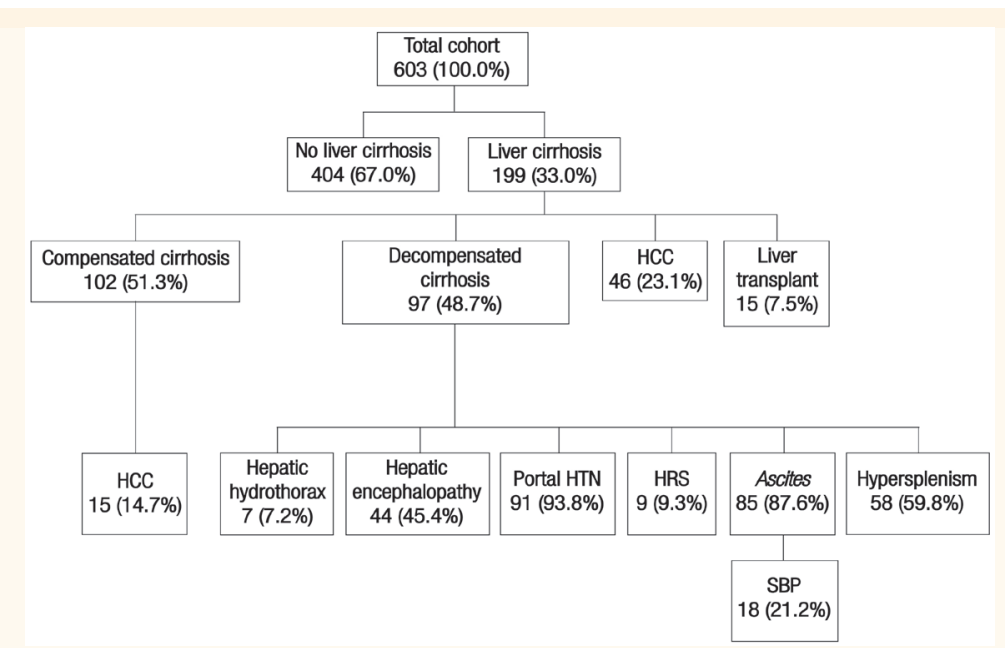

Figure 3: Diagram showing the clinical outcomes* of chronic hepatitis C-infected patients presenting to the Sultan Qaboos University Hospital, Muscat, Oman $(\mathrm{N}=603)$.

$H C C=$ hepatocellular carcinoma; $H T N=$ hypertension; $H R S=$ hepatorenal syndrome; SBP = spontaneous bacterial peritonitis .

"Percentages for some outcomes add up to more than $100 \%$ as some patients may have reported multiple outcomes.

increased availability of illegal drugs. ${ }^{17}$ However, it is also possible that some patients living in other governorates in Oman were referred to other hospitals apart from SQUH during the study period.

Globally, the distribution of $\mathrm{HCV}$ genotypes differs according to epidemiological variations, including differences in modes of transmission and ethnic and temporal factors. ${ }^{16}$ However, there is a paucity of data regarding the distribution of $\mathrm{HCV}$ genotypes in Oman. Al-Naamani et al. previously reported the genotype distribution of 33 multi-transfused $\beta$-thalassaemia Omani patients to be 55\%, 27\%, 9\% and 9\% for genotypes 1, 4, 2 and 3, respectively. ${ }^{12}$ However, in the current study, genotype 1 was most prevalent (44.0\%), followed by genotypes 3 (35.1\%), 4 (15.0\%), 2 (3.7\%) and mixed (2.2\%). This discrepancy in findings could be due to the fact that Al-Naamani et al's study focused purely on a subset of multi-transfused thalassaemic patients; these patients were most likely infected from transfused blood imported to Oman before 1991, when HCV screening first began. ${ }^{12}$ The prevalence of genotype 1 over other genotypes in the current study was similar to reports from other Middle Eastern countries like the United Arab Emirates (UAE; 49.2\%), Turkey (95.6\%), Iran (56.2\%) and Bahrain (37\%). ${ }^{18-21}$ However, other studies from Saudi Arabia, Yemen and Iraq found that genotype 4 was most frequent. ${ }^{22-24}$

In the current study, alcohol and tobacco use were relatively uncommon. Nevertheless, alcohol consumption and smoking are well-known risk factors for disease progression to liver cirrhosis and HCC among $\mathrm{CHC}$ patients. ${ }^{25}$ Moreover, alcohol intake may be associated with other risky behaviours; as such, this factor should be considered a potential target for $\mathrm{HCV}$ screening. ${ }^{26}$ Almost half of the patients in the current cohort were first diagnosed with $\mathrm{CHC}$ based on existing evidence of liver disease, such as elevated liver enzymes, deranged liver function or imaging findings. Moreover, this subgroup of patients had a much higher prevalence of cirrhosis and HCC compared to asymptomatic patients who were diagnosed as a result of routine screening. This finding emphasises the importance of early HCV screening and diagnosis in high-risk populations; indeed, this may be especially effective in improving clinical outcomes coupled with the newfound availability of highly effective antiviral regimens. ${ }^{27}$

Nearly a quarter of the $\mathrm{CHC}$ patients in the present study were infected as a result of intravenous drug abuse; of these, the majority had genotypes 3 and 1 . A similarly high prevalence of genotypes 3 and 1 has been reported among intravenous drug users in France and the UAE. ${ }^{18,28}$ Blood transfusions were the second most common mode of HCV transmission in the current study, with genotypes 1 followed by 3 being most prevalent among affected individuals. In contrast, Shahraki et al. found that genotype 3a (40\%) was most prevalent among transfused thalassaemic patients in Iran, followed by genotype $1 \mathrm{~b}(25 \%){ }^{29}$ Critically, the findings of the current study indicate that blood transfusion is still a possible risk factor for $\mathrm{HCV}$ transmission in Oman despite the routine screening of transfused blood. This may be potentially due to the use of serological testing instead of advanced screening techniques such as nucleic acid amplification. ${ }^{30}$

A history of surgery is another risk factor for $\mathrm{HCV}$ infection due to the role that contaminated surgical equipment can play in the transmission of blood-borne 
diseases. The incidence of surgery-associated HCV infections caused by breaches in infection control practices have been previously reported in the USA. ${ }^{31}$ In the current study, many of the surgeries reported by $\mathrm{CHC}$ patients were performed before routine $\mathrm{HCV}$ screening was initiated prior to invasive surgeries. In addition, many of the surgeries were carried out abroad; as such, adherence to blood-borne pathogen screening protocols at such institutions was unknown. Therefore, public awareness of the importance of presurgical HCV screening should be increased in Oman; in addition, local infection control policies and procedures at governmental hospitals should be reviewed to ensure that surgical equipment is adequately disinfected.

Approximately one-third of the patients in the present study did not report any risk factors for $\mathrm{HCV}$, which is similar to other findings reported in the literature. ${ }^{32}$ This suggests the presence of other unidentified modes of HCV transmission in Oman, such as traditional healers, body piercings, barber shops and professional pedicures/manicures. Another important finding was that many $\mathrm{HCV}$-infected patients in the current study also had advanced liver disease, including decompensated cirrhosis and HCC; moreover, many of the HCC cases were beyond the Milan transplantation criteria. ${ }^{14}$ This prevalence of advanced HCV-related complications upon presentation is high in comparison to other research. ${ }^{27}$ Further studies are therefore needed to assess risk factors for cirrhosis and HCV-related outcomes among Omani patients. The current study also showed a low rate of liver transplantation amongst $\mathrm{CHC}$-infected patients with decompensated cirrhosis. Since Oman does not have a liver transplant service, candidates are usually sent abroad for the procedure as long as they can find a willing and compatible living adult donor. The generalisability of the results of the current study was limited by the retrospective nature of the study and the fact that participants were selected from a single tertiary health care facility.

\section{Conclusion}

In the current study, major risk factors for $\mathrm{HCV}$ transmission included intravenous drug abuse and blood transfusions, with genotypes 1 and 3 being most frequent. Moreover, patients diagnosed with $\mathrm{CHC}$ via routine screening had lower morbidity compared to patients who were only diagnosed as a result of existing signs of liver disease. Therefore, the implementation of national policies to prevent HCV transmission and encourage the early screening of at-risk individuals and prompt management of $\mathrm{HCV}$ cases is highly recommended. In addition, more studies are needed to understand the prevalence of and risk factors for poor HCV-related outcomes in Oman.

\section{CONFLICT OF INTEREST}

The authors declare no conflicts of interest.

\section{FUNDING}

No funding was received for this study.

\section{References}

1. Petruzziello A, Marigliano S, Loquercio G, Cozzolino A, Cacciapuoti C. Global epidemiology of hepatitis C virus infection: An up-date of the distribution and circulation of hepatitis C virus genotypes. World J Gastroenterol 2016; 22:7824-40. doi: 10.3748/wjg.v22.i34.7824.

2. Alberti A, Chemello L, Benvegnù L. Natural history of hepatitis C. J Hepatol 1999; 31:17-24. doi: 10.1016/S01688278(99)80369-9.

3. Kanwal F, Hoang T, Kramer JR, Asch SM, Goetz MB, Zeringue $\mathrm{A}$, et al. Increasing prevalence of $\mathrm{HCC}$ and cirrhosis in patients with chronic hepatitis $\mathrm{C}$ virus infection. Gastroenterology 2011; 140:1182-8. doi: 10.1053/j.gastro.2010. 12.032 .

4. Bandiera S, Billie Bian C, Hoshida Y, Baumert TF, Zeisel MB. Chronic hepatitis $\mathrm{C}$ virus infection and pathogenesis of hepatocellular carcinoma. Curr Opin Virol 2016; 20:99-105. doi: 10.1016/j.coviro.2016.09.010.

5. Coffin PO, Reynolds A. Ending hepatitis $C$ in the United States: The role of screening. Hepat Med 2014; 6:79-87. doi: 10.2147/ HMER.S40940.

6. Denniston MM, Jiles RB, Drobeniuc J, Klevens RM, Ward JW, McQuillan GM, et al. Chronic hepatitis C virus infection in the United States, National Health and Nutrition Examination Survey 2003 to 2010. Ann Intern Med 2014; 160:293-300. doi: 10.7326/M13-1133.

7. Talaat N, Yapali S, Fontana RJ, Conjeevaram HS, Lok AS Changes in characteristics of hepatitis $C$ patients seen in a liver centre in the United States during the last decade. J Viral Hepat 2015; 22:481-8. doi: 10.1111/jvh.12343.

8. Sulkowski MS, Thomas DL. Hepatitis C in the HIV-infected person. Ann Intern Med 2003; 138:197-207. doi: 10.7326/00034819-138-3-200302040-00012.

9. Verucchi G, Calza L, Manfredi R, Chiodo F. Human immunodeficiency virus and hepatitis $\mathrm{C}$ virus coinfection: Epidemiology, natural history, therapeutic options and clinical management. Infection 2004; 32:33-46. doi: 10.1007/s15010004-3063-7.

10. Elgouhari HM, Zein CO, Hanouneh I, Feldstein AE, Zein NN. Diabetes mellitus is associated with impaired response to antiviral therapy in chronic hepatitis C infection. Dig Dis Sci 2009; 54:2699-705. doi: 10.1007/s10620-008-0683-2.

11. Caccamo G, Saffioti F, Raimondo G. Hepatitis B virus and hepatitis C virus dual infection. World J Gastroenterol 2014; 20:14559-67. doi: 10.3748/wjg.v20.i40.14559.

12. Al-Naamani K, Al-Zakwani I, Al-Sinani S, Wasim F, Daar S. Prevalence of hepatitis C among multi-transfused thalassaemic patients in Oman: Single centre experience. Sultan Qaboos Univ Med J 2015; 15:e46-51.

13. al-Dhahry SH, Aghanashinikar PN, al-Hasani MK, Buhl MR, Daar AS. Antibodies to hepatitis C virus in Omani patients with renal disease. Transplant Proc 1992; 24:1938-9. 
14. Mazzaferro V, Regalia E, Doci R, Andreola S, Pulvirenti A, Bozzetti F, et al. Liver transplantation for the treatment of small hepatocellular carcinomas in patients with cirrhosis. N Engl J Med 1996; 334:693-9. doi: 10.1056/NEJM199603143341104.

15. Liang TJ, Rehermann B, Seeff LB, Hoofnagle JH. Pathogenesis, natural history, treatment, and prevention of hepatitis C. Ann Intern Med 2000; 132:296-305. doi: 10.7326/0003-4819-132-4200002150-00008.

16. Hajarizadeh B, Grebely J, Dore GJ. Case definitions for acute hepatitis C virus infection: A systematic review. J Hepatol 2012; 57:1349-60. doi: 10.1016/j.jhep.2012.07.007.

17. Ruta S, Cernescu C. Injecting drug use: A vector for the introduction of new hepatitis $\mathrm{C}$ virus genotypes. World J Gastroenterol 2015; 21:10811-23. doi: 10.3748/wjg.v21.i38. 10811 .

18. Abro AH, Al-Dabal L, Younis NJ. Distribution of hepatitis C virus genotypes in Dubai, United Arab Emirates. J Pak Med Assoc 2010; 60:987-90

19. Bozdayi AM, Aslan N, Bozdayi G, Türkyilmaz AR, Sengezer T, Wend U, et al. Molecular epidemiology of hepatitis B, C and D viruses in Turkish patients. Arch Virol 2004; 149:2115-29. doi: 10.1007/s00705-004-0363-2.

20. Jahanbakhsh Sefidi F, Keyvani H, Monavari SH, Alavian SM, Fakhim S, Bokharaei-Salim F. Distribution of hepatitis C virus genotypes in Iranian chronic infected patients. Hepat Mon 2013; 13:e7991. doi: 10.5812/hepatmon.7991.

21. Ghaderi-Zefrehi H, Gholami-Fesharaki M, Sharafi $H$, Sadeghi F, Alavian SM. The distribution of hepatitis $C$ virus genotypes in Middle Eastern countries: A systematic review and meta-analysis. Hepat Mon 2016; 16:e40357. doi: 10.5812/ hepatmon. 40357

22. Shobokshi OA, Serebour FE, Skakni L, Al-Saffy YH, Ahdal MN Hepatitis C genotypes and subtypes in Saudi Arabia. J Med Virol 1999; 58:44-8. doi: 10.1002/(SICI)1096-9071(199905)58: $1<44::$ AID-JMV6>3.0.CO;2-U.

23. Ohno T, Mizokami M, Saleh MG, Orito E, Ohba KI, Wu RR, et al. Usefulness and limitation of phylogenetic analysis for hepatitis $\mathrm{C}$ virus core region: Application to isolates from Egyptian and Yemeni patients. Arch Virol 1996; 141:1101-13.
24. Al-Kubaisy WA, Al-Naib KT, Habib M. Seroprevalence of hepatitis $\mathrm{C}$ virus specific antibodies among Iraqi children with thalassaemia. East Mediterr Health J 2006; 12:204-10.

25. Di Costanzo GG, De Luca M, Tritto G, Lampasi F, Addario L, Lanza AG, et al. Effect of alcohol, cigarette smoking, and diabetes on occurrence of hepatocellular carcinoma in patients with transfusion-acquired hepatitis $\mathrm{C}$ virus infection who develop cirrhosis. Eur J Gastroenterol Hepatol 2008; 20:674-9. doi: 10.1097/MEG.0b013e3282f762e1.

26. Abdo AA, Sanai FM, Al-Faleh FZ. Epidemiology of viral hepatitis in Saudi Arabia: Are we off the hook? Saudi J Gastroenterol 2012; 18:349-57. doi: 10.4103/1319-3767.103425

27. Konerman MA, Yapali S, Lok AS. Systematic review: Identifying patients with chronic hepatitis $\mathrm{C}$ in need of early treatment and intensive monitoring - Predictors and predictive models of disease progression. Aliment Pharmacol Ther 2014; 40:863-79. doi: 10.1111/apt.12921.

28. Pawlotsky JM, Tsakiris L, Roudot-Thoraval F, Pellet C, Stuyver L, Duval J, et al. Relationship between hepatitis $C$ virus genotypes and sources of infection in patients with chronic hepatitis C. J Infect Dis 1995; 171:1607-10. doi: 10.1093/infdis/171.6.1607.

29. Shahraki T, Shahraki M, Moghaddam ES, Najafi M, Bahari A. Determination of hepatitis $\mathrm{C}$ genotypes and the viral titer distribution in children and adolescents with major thalassemia. Iranian J Pediatr 2010; 20:75-81.

30. Marwaha N, Sachdev S. Current testing strategies for hepatitis $\mathrm{C}$ virus infection in blood donors and the way forward. World J Gastroenterol 2014; 20:2948-54. doi: 10.3748/wjg.v20.i11.2948.

31. Perz JF, Grytdal S, Beck S, Fireteanu AM, Poissant T, Rizzo E, et al. Case-control study of hepatitis B and hepatitis C in older adults: Do healthcare exposures contribute to burden of new infections? Hepatology 2013; 57:917-24. doi: 10.1002/ hep. 25688 .

32. Karmochkine M, Carrat F, Dos Santos O, Cacoub P, Raguin G. A case-control study of risk factors for hepatitis $\mathrm{C}$ infection in patients with unexplained routes of infection. J Viral Hepat 2006; 13:775-82 doi: 10.1111/j.1365-2893.2006.00742x. 